\title{
Gender and obesity modify the impact of salt intake on blood pressure in children
}

\author{
Liane Correia-Costa ${ }^{1,2,12} \cdot$ Dina Cosme ${ }^{1,3} \cdot$ Luís Nogueira-Silva ${ }^{4,5}$. \\ Manuela Morato ${ }^{3,6,7}$ - Teresa Sousa ${ }^{3,6} \cdot$ Cláudia Moura $^{8} \cdot$ Cláudia Mota $^{8}$. \\ António Guerra $^{5,9}$ - António Albino-Teixeira ${ }^{3,6}$ • José Carlos Areias ${ }^{8}$. \\ Franz Schaefer $^{10}$ • Carla Lopes ${ }^{1,11}$ - Alberto Caldas Afonso ${ }^{1,2}$ • Ana Azevedo ${ }^{1,11}$
}

Received: 9 June 2015 /Revised: 2 September 2015 / Accepted: 3 September 2015 / Published online: 29 September 2015

(C) IPNA 2015

\begin{abstract}
Background Most modifiable risk factors for high blood pressure (BP), such as obesity and salt intake, are imprinted in childhood and persist into adulthood. The aim of our study was to evaluate the intake of salt in children and to assess its impact on BP taking into account gender and nutritional status.

Methods A total of 298 children aged 8-9 years were evaluated in a cross-sectional study. Anthropometric measurements and 24-h ambulatory monitoring were performed, and salt intake was determined by 24-h urinary sodium excretion.

Results The average estimated salt intake among the entire cohort of children enrolled in the study was $6.5 \pm 2.2 \mathrm{~g} /$ day, and it was significantly higher in boys than in girls $(6.8 \pm 2.4$ vs. $6.1 \pm 1.9 \mathrm{~g} /$ day, respectively; $p=0.018)$ and in overweight/ obese children than in normal weight children $(6.8 \pm 2.4$ vs.
\end{abstract}

Liane Correia-Costa and Dina Cosme contributed equally to this work.

Liane Correia-Costa

liane@med.up.pt

1 Epidemiology Research Unit (EPIUnit), Institute of Public Health, University of Porto, Porto, Portugal

2 Division of Pediatric Nephrology, Integrated Pediatric Hospital, Centro Hospitalar São João, Porto, Portugal

3 Department of Pharmacology and Therapeutics, Faculty of Medicine of University of Porto, Porto, Portugal

4 Department of Internal Medicine, Centro Hospitalar São João, Porto, Portugal

5 Center for Research in Health Technologies and Information Systems (CINTESIS), Faculty of Medicine, University of Porto, Porto, Portugal

6 Center for Drug Discovery and Innovative Medicines (MedInUP), University of Porto, Porto, Portugal
$6.1 \pm 2.0 \mathrm{~g} /$ day, respectively; $p=0.006)$. Salt intake exceeded the upper limit of the US Dietary Reference Intake in $72 \%$ of children. Daytime systolic BP increased by $1.00 \mathrm{mmHg}$ (95\% confidence interval $0.40-1.59)$ per gram of daily salt intake in overweight/obese boys, but not in normal weight boys or in girls.

Conclusions Our results demonstrate an extremely high salt intake among 8- to 9-year-old Portuguese children. Higher salt intake was associated with higher systolic BP in boys, specifically in those who were overweight/obese. Longitudinal studies are needed to further evaluate the causal relationship between obesity and high BP and the mechanism by which salt intake modulates this relationship. Nonetheless, based on our results, we urge that dietary salt reduction interventions, along with measures to fight the global epidemic of obesity, be implemented as early in life as possible.

7 Laboratory of Pharmacology, Department of Drug Sciences, Faculty of Pharmacy of Porto, University of Porto, Porto, Portugal

8 Division of Pediatric Cardiology, Integrated Pediatric Hospital, Centro Hospitalar São João, Porto, Portugal

9 Division of Pediatric Nutrition, Integrated Pediatric Hospital, Centro Hospitalar São João, Porto, Portugal

10 Division of Pediatric Nephrology, Center for Pediatrics and Adolescent Medicine, University of Heidelberg, Heidelberg, Germany

11 Department of Clinical Epidemiology, Predictive Medicine and Public Health, Faculty of Medicine of University of Porto, Porto, Portugal

12 Instituto de Saúde Pública da Universidade do Porto (ISPUP), Rua das Taipas n 135, 4050-600 Porto, Portugal 
Keywords Salt intake $\cdot$ Blood pressure $\cdot$ Hypertension . Obesity $\cdot$ Children $\cdot$ Gender

\section{Introduction}

High blood pressure (BP) is the leading risk factor for global disease burden [1], and its prevalence in childhood and adolescence has increased over the last decades [2]. High blood pressure during early life stages has been shown to track into adult life [3] and not expectedly to also contribute to an increase in cardiovascular morbidity and mortality [4], especially among overweight youth [5, 6]. In addition, most of the modifiable risk factors for high BP are known to be imprinted in childhood and to persist. Consequently, it is crucial to address these issues early in life in order to reduce the burden of disease in adults [7]. In children, there is increasing evidence that obesity and high salt intake are not only important risk factors for hypertension, but possibly also the two most important modifiable risk factors.

The trendline for prevalence of hypertension parallels that for the obesity epidemic $[2,8]$, and a recent meta-analysis which included studies in children has shown that salt intake is closely associated with BP $[9,10]$. This is of particular concern as there is evidence of a "programming" effect between salt intake in early childhood and BP later in life [11, 12] and of overweight and obese individuals being more salt sensitive [13]. Some studies in adults and adolescents have suggested that the presence of obesity might strengthen the effect of salt on BP $[14,15]$, but few studies have studied this issue in children $[16,17]$.

Although the importance of dietary salt reduction has been globally acknowledged, the salt intake of many children in several countries around the world children is well above the recommended amount [18]. Given the importance of identifying the best preventive measures for hypertension, there are several reasons why studying the effects of salt intake on BP should take into account the nutritional status of the subjects and why the study of these interlinked actions should be assessed as early as possible in childhood. A recent study among the Portuguese general population revealed that Portugal is one of the leading countries in salt consumption [19]. We have therefore evaluated the intake of salt (by 24-h urine estimation) in a sample of 8- to 9-year-old children and assessed its overall impact on ambulatory BP values, taking into consideration the gender and body mass index (BMI) of the children.

\section{Methods}

\section{Study design and sample}

We studied children aged 8-9 years old who have been followed since birth in a previously established cohort study
(Generation XXI, Porto, Portugal) [20]. Of the original cohort $(n=8647), 4590$ children participated in a face-to-face followup visit at 7 years of age, including an anthropometric evaluation and blood sample collection. These children were eligible to participate in the ObiKid project - a project with the specific aim to clarify the impact of childhood obesity and associated comorbidities on the kidney. We defined a minimum sample of 300 children for the ObiKid project's main objective. To obtain this sample, we consecutively screened children according to the date of their 7-year-old evaluation. Exclusion criteria were chronic diseases (genetic, renal or metabolic), chronic usage of medication (affecting BP or glucose or lipid metabolism), and residence located $>30 \mathrm{~km}$ from the study site; twins were also excluded. This sample size provides a statistical power of about $95 \%$ to detect a mean difference in daytime systolic BP (SBP) of about $0.4 \mathrm{mmHg}$ per gram of salt intake [21].

\section{Data collection and definition of variables}

Study visits took place at the Department of Clinical Epidemiology, Predictive Medicine and Public Health, Faculty of Medicine of the University of Porto, between August 2013 and August 2014. Data on each child and family medical history were collected by means of a structured questionnaire. Children were considered to have a family history of hypertension when at least one parent or sibling was reported to be affected. Classes of gender-specific adequate birth weight for gestational age were defined according to the population-based Canadian reference curves $(<10$ th percentile, small for gestational age; $\geq 10$ th percentile and $<90$ th percentile, adequate for gestational age; $\geq 90$ th percentile, large for gestational age) [22]. The anthropometric and general physical examinations were performed according to standard procedures and as previously reported [23]. The BMI was calculated, and BMI-for-age values were classified according to the World Health Organization reference data for BMI $z$-scores into the following categories: normal weight $[\leq+1$ standard deviation (SD), including 1 child classified as being thin] and overweight/obesity ( $>1 \mathrm{SD}$, including children who were overweight and obesity) [24].

Ambulatory BP monitoring (ABPM) for $24 \mathrm{~h}(24-\mathrm{h}$ ABPM) was performed in all children with a portable noninvasive oscillometric BP recorder (model 90207; Spacelabs Healthcare ${ }^{\circledR}$, Snoqualmie, WA). The non-dominant arm was used in all children with a cuff size chosen according to patient's arm circumference. BP measurements were taken automatically at 20-min intervals during the daytime and at 30-min intervals during the nighttime. A minimum monitoring duration of $24 \mathrm{~h}$ with gaps of $<2 \mathrm{~h}$ was required for the data to be acceptable for analysis; consequently, monitoring data from five children were excluded from the ABPM analysis due to insufficient readings ( $<40$ readings in $24 \mathrm{~h}$ or $<1$ reading per 
hour during sleep). The readings were analyzed to calculate mean 24-h BP, day and night mean arterial pressure (MAP), SBP and diastolic BP (DBP) using SpaceLabs ${ }^{\circledR}$ Healthcare software. Office BP was evaluated with oscillometric validated sphygmomanometers (Elite 92125; Medel, Parma, Italy) with an adequately sized cuff on the right arm, by a trained non-physician interviewer. On each occasion, the office BP was measured three times with a 5-min interval between measurements, and the second and third measurements were averaged for further analysis. Sustained hypertension [25] was defined as (1) average SBP and/or DBP measurements of $\geq 95$ th percentile, during the day or during the night on ABPM, according to the reference values [25], (2) a SBP or DPB load of $\geq 25 \%$ during the day or night, and (3) an office SBP and/or DBP of $\geq 95$ th percentile [26], according to the American Heart Association criteria. When office BP values were $<95$ th percentile, but the remaining criteria were satisfied, the children were classified as presenting masked hypertension [25]. To characterize the circadian BP rhythmicity on ABPM we calculated the percentage of nocturnal fall in MAP using the formula: [(mean daytime MAP - mean nighttime MAP)/mean daytime MAP] $\times 100$. The absence of dipping pattern was considered as a fall in the MAP during nighttime of $<10 \%$ of the corresponding daytime BP.

\section{Laboratory procedures}

A 24-h urine sample was collected from all participants and analyzed for creatinine and sodium. The 24-h urine samples were considered valid if urinary creatinine was within the range of $11.3-28.0 \mathrm{mg} / \mathrm{kg} /$ day (according to age- and sexspecific reference values [27]) and if urinary volume was $>300 \mathrm{~mL}$. The parents of each child received information on the correct methods for collecting the 24-h urine sample, and upon sample delivery compliance was rechecked with a brief questionnaire. Based on these criteria, 15 urine samples were excluded from the analysis. All laboratory analyses were performed in the Clinical Pathology Department of Centro Hospitalar São João. Sodium level in the urine was determined by an ion-selective electrode method, and creatinine was determined by a standard automated clinical chemistry analyzer (Olympus AU 5400 automated analyzer; BeckmanCoulter ${ }^{\circledR}$, Brea, California). The estimated salt intake was derived from 24-h urinary sodium excretion as $1 \mathrm{mEq}$ of sodium being equal to $0.0588 \mathrm{~g}$ of salt. We used two different criteria for considering the estimated salt intake as excessive: (1) $>4.85 \mathrm{~g} /$ day for 4 - to 8 -year-olds and $>5.61 \mathrm{~g} /$ day for 9 - to 13-year-olds, which are the upper limits of the US Dietary Reference Intakes of the Food and Nutrition Board of the Institute of Medicine [28]; (2) $>3 \mathrm{~g} /$ day for 8 -year-olds or younger and $>4 \mathrm{~g} /$ day for 9 - to 11 -year-olds, according to the body surface-area-based recommendations for salt intake in children by Marrero et al. [29].

\section{Statistical analysis}

Standard statistical analysis was performed using IBM SPSS Statistics for Windows, version 20.0 (IBM Corp., Armonk, $\mathrm{NY})$ ). We used $t$ tests to compare independent means of continuous variables and chi-square tests to compare proportions between genders. Linear regression models were used to quantify the impact of estimated salt intake on several ABPM variables, and multiple linear regression models were used to account for the effect of birthweight-for-gestational age, age, BMI $z$-score and family history of hypertension, in that association, in the whole sample and separately in normal weight and overweight children.

\section{Results}

Among the children who were screened for entry into the study, 68 met the exclusion criteria [4 with chronic diseases (genetic, renal or metabolic), 1 with chronic usage of medication (affecting BP or glucose or lipid metabolism), 51 who resided $<30 \mathrm{~km}$ from the study site, and six pairs of twins]. An additional 16 children could not be contacted, 32 refused to participate, and 23 although willing to participate were unable to schedule the study visits during the recruitment period. Finally, 324 children were enrolled but, for the present analysis, 11 children were excluded due to incomplete evaluation(s) and 15 were excluded because of invalid 24-h urine samples.

The 298 children who ultimately participated in the study had a mean (SD) age of $8.8(0.2)$ years. General characteristics and ABPM values are shown separately for girls $(n=139)$ and boys $(n=159)$ in Table 1 . Boys presented with significantly higher BMI $z$-score values and a higher prevalence of obesity than girls. No significant differences were found between genders in mean BP values based on the 24-h ABPM. The prevalence of sustained hypertension was $1.4 \%$ in girls and $3.8 \%$ in boys. Loss of the dipping pattern was observed in $23 \%$ of girls and $29 \%$ of boys $(p=0.250)$ (Table 1 ).

The average estimated salt intake for the entire study population was $6.5 \pm 2.2 \mathrm{~g} /$ day and was significantly higher in boys than in girls $(6.8 \pm 2.4$ vs. $6.1 \pm 1.9 \mathrm{~g} /$ day, respectively; $p=0.018$ ). Overall, the salt intake of $72 \%$ of the children was above the upper limit of the US Dietary Reference Intakes, and in $95 \%$ of the children it was above the adapted recommendations for children, based on body surface area (Table 2). A significant linear trend of higher salt intake across classes of BMI was found, both in boys ( $p$ for trend $=0.038$ ) and in girls ( $p$ for trend $=0.002$ ). The estimated salt intake was $7.2 \pm 2.3$ and $7.5 \pm 2.7 \mathrm{~g} /$ day in obese girls and obese boys, respectively (Fig. 1). In the first tertile of salt intake, two (2\%) children were hypertensive; in the second tertile one $(1 \%)$ child was hypertensive; in the third tertile five $(5.1 \%)$ children were hypertensive. Among the six boys with hypertension, one 
Table 1 General characteristics, blood pressure variables and estimated salt intake of the study population according to gender

\begin{tabular}{|c|c|c|c|}
\hline Variable & Girls $(n=139)$ & Boys $(n=159)$ & $p$ \\
\hline \multicolumn{4}{|l|}{ Demographic and anthropometric variables } \\
\hline Age (months) & $105.1 \pm 2.9$ & $105.3 \pm 2.9$ & 0.676 \\
\hline BMI $z$-score & $0.81 \pm 1.21$ & $1.07 \pm 1.25$ & 0.043 \\
\hline Overweight/obesity $^{\mathrm{a}}$ & $46(33 \%) / 18(13 \%)$ & $41(26 \%) / 39(25 \%)$ & 0.033 \\
\hline Family history of hypertension ${ }^{\mathrm{b}}$ & $28(20 \%)$ & $28(18 \%)$ & 0.629 \\
\hline \multicolumn{4}{|l|}{ Birth weight for gestational age ${ }^{c}$} \\
\hline Small $(<10$ th percentile $)$ & $16(12 \%)$ & $22(14 \%)$ & \\
\hline Adequate (10th-90th percentile) & $116(83 \%)$ & $131(82 \%)$ & 0.742 \\
\hline Large ( $\geq 90$ th percentile) & $7(5 \%)$ & $6(4 \%)$ & \\
\hline \multicolumn{4}{|l|}{ Office blood pressure } \\
\hline SBP $(\mathrm{mmHg})$ & $102.7 \pm 9.1$ & $103.9 \pm 8.4$ & 0.235 \\
\hline $\mathrm{DBP}(\mathrm{mmHg})$ & $64.5 \pm 7.5$ & $64.7 \pm 6.8$ & 0.815 \\
\hline \multicolumn{4}{|l|}{ 24-h ambulatory blood pressure } \\
\hline Daytime SBP (mmHg) & $115.9 \pm 8.7$ & $116.9 \pm 7.0$ & 0.282 \\
\hline Daytime DBP (mmHg) & $70.7 \pm 5.6$ & $70.9 \pm 4.7$ & 0.756 \\
\hline Daytime MAP (mmHg) & $85.5 \pm 4.9$ & $85.2 \pm 6.0$ & 0.654 \\
\hline Nighttime SBP (mmHg) & $103.6 \pm 8.2$ & $104.2 \pm 6.2$ & 0.492 \\
\hline Nighttime DBP (mmHg) & $58.4 \pm 6.2$ & $58.6 \pm 4.7$ & 0.737 \\
\hline Nighttime MAP (mmHg) & $74.3 \pm 4.5$ & $74.0 \pm 6.2$ & 0.663 \\
\hline Non-dipping status ${ }^{\mathrm{d}}$ & $32(23 \%)$ & $46(29 \%)$ & 0.250 \\
\hline Sustained hypertension / Masked hypertension ${ }^{\mathrm{e}}$ & $2(1.4 \%) / 15(10.8 \%)$ & $6(3.8 \%) / 5(3.1 \%)$ & - \\
\hline \multicolumn{4}{|l|}{ Estimated salt intake } \\
\hline Urinary sodium excretion (mEq/24 h) & $104.5 \pm 33.7$ & $114.9 \pm 41.0$ & 0.018 \\
\hline Salt equivalent (g/24 h) & $6.1 \pm 1.9$ & $6.8 \pm 2.4$ & 0.018 \\
\hline Salt intake above 4.8 or $5.6 \mathrm{~g} / \mathrm{day}^{\mathrm{f}}$ & $97(70 \%)$ & $117(74 \%)$ & 0.467 \\
\hline Salt intake above 3 or $4 \mathrm{~g} /$ day $^{\mathrm{g}}$ & $132(95 \%)$ & $151(95 \%)$ & 0.999 \\
\hline
\end{tabular}

Values are presented as the mean \pm standard deviation (SD) or as a number $(n)$ with the percentage in parenthesis, as appropriate $B M I$ body mass index, $S B P$ systolic blood pressure, $D B P$ diastolic blood pressure, $M A P$ mean arterial pressure

${ }^{\text {a }}$ The classification of overweight and obesity is according to the World Health Organization classification for BMI $z$-scores [24]

${ }^{\mathrm{b}}$ Children were considered to have a family history of hypertension when at least one parent or sibling was reported to be affected

${ }^{\mathrm{c}}$ Birthweight for gestational age according to the population-based Canadian reference curves [22]

${ }^{\mathrm{d}}$ Non-dipping status was defined as a fall in the MAP during nighttime of $<10 \%$ of the corresponding daytime BP

${ }^{\mathrm{e}}$ Sustained hypertension and masked hypertension were defined according to the revised American Heart Association criteria for interpretation of ambulatory BP monitoring (ABPM) data [25]

${ }^{\mathrm{f}}$ According to the upper limit of the US Dietary Reference Intakes of the Food and Nutrition Board of the Institute of Medicine $(\leq 4.8 \mathrm{~g}$ salt/day for 4 - to 8-year-olds and $\leq 5.6 \mathrm{~g}$ salt/day for 9 - to 13 -year-olds) [28]

${ }^{\mathrm{g}}$ According to the body surface area-based recommendations for salt intake in children ( $\leq 3 \mathrm{~g}$ salt/day for $\leq 8$-year-olds and $\leq 4 \mathrm{~g}$ salt/day for 9 - to 11 -year-olds), by Marrero et al. [29]

$(2 \%)$ was in the first tertile of salt intake and five $(8.3 \%)$ were in the third tertile. Among the two hypertensive girls, one $(2 \%)$ was in the first tertile and one $(2 \%)$ was in the second tertile.

In girls, we observed a decrease of daytime DBP values in the overall group and of nighttime DBP in the overweight/ obese group across all tertiles of salt intake (Fig. 2). In boys, we observed increasing BP values across salt intake tertiles, which were significant for daytime SBP and DBP in both the overall [(presented as 1st vs. 2nd vs. 3rd tertile) SBP: $114.8 \pm 7.3$ vs. $117.3 \pm 5.9$ vs. $118.2 \pm 7.4 \mathrm{mmHg}$, $p_{\text {trend }}=0.006 ;$ DBP: $69.8 \pm 4.7$ vs. $71.1 \pm 4.7$ vs. $71.6 \pm$ $\left.4.6 \mathrm{mmHg}, p_{\text {trend }}=0.043\right]$ and the overweight/obese groups (SBP: $114.3 \pm 7.8$ vs. $117.6 \pm 6.2$ vs. $120.6 \pm 6.9 \mathrm{mmHg}$, $p_{\text {trend }}<0.001$; DBP: $68.4 \pm 4.5$ vs. $71.0 \pm 5.4$ vs. $71.7 \pm$ $4.6 \mathrm{mmHg}, p_{\text {trend }}=0.027$ ), and for nighttime SBP only in the overweight/obese group (SBP: $103.7 \pm 6.0$ vs. $104.9 \pm$ 5.0 vs. $106.3 \pm 6.9 \mathrm{mmHg}, p_{\text {trend }}=0.041$ ) (Fig. 2). 
Table 2 Mean change in blood pressure by each gram of estimated salt intake per day, in girls and boys separately

\begin{tabular}{|c|c|c|c|c|c|c|c|c|}
\hline \multirow[t]{3}{*}{ Models $^{\mathrm{a}}$} & \multicolumn{4}{|l|}{ Daytime SBP } & \multicolumn{4}{|l|}{ Nighttime SBP } \\
\hline & Girls & & Boys & & Girls & & Boys & \\
\hline & $\beta(95 \% \mathrm{CI})$ & $p$ & $\beta(95 \% \mathrm{CI})$ & $p$ & $\beta(95 \% \mathrm{CI})$ & $p$ & $\beta(95 \% \mathrm{CI})$ & $p$ \\
\hline Model 1 & $0.01(-0.78$ to 0.80$)$ & 0.976 & $0.56(0.11-1.01)$ & 0.014 & $-0.21(-0.95$ to 0.52$)$ & 0.571 & $0.27(-0.14$ to 0.67$)$ & 0.195 \\
\hline Model $1+$ BMI $z$-score & $-0.04(-0.84$ to 0.75$)$ & 0.918 & $0.53(0.08-1.00)$ & 0.022 & $-0.31(-1.03$ to 0.42$)$ & 0.408 & $0.23(-0.18$ to 0.63$)$ & 0.273 \\
\hline \multicolumn{9}{|l|}{ Normal weight } \\
\hline Model 1 & $-0.24(-1.38$ to 0.91$)$ & 0.682 & $-0.18(-0.91$ to 0.55$)$ & 0.623 & $0.16(-0.86$ to 1.19$)$ & 0.752 & $-0.25(-0.91$ to 0.42$)$ & 0.460 \\
\hline \multicolumn{9}{|l|}{ Overweight/Obese } \\
\hline \multirow[t]{4}{*}{ Model 1} & $0.09(-1.11$ to 1.30$)$ & 0.878 & $1.00(0.40-1.59)$ & $0.001^{\mathrm{b}}$ & $-0.68(-1.79$ to 0.42$)$ & 0.222 & $0.48(-0.06$ to 1.03$)$ & 0.080 \\
\hline & Daytime DBP & & & & Nighttime DBP & & & \\
\hline & Girls & & Boys & & Girls & & Boys & \\
\hline & $\beta(95 \% \mathrm{CI})$ & $p$ & $\beta(95 \% \mathrm{CI})$ & $p$ & $\beta(95 \% \mathrm{CI})$ & $p$ & $\beta(95 \% \mathrm{CI})$ & $p$ \\
\hline Model 1 & $-0.35(-0.87$ to 0.17$)$ & 0.180 & $0.30(-0.02$ to 0.63$)$ & 0.066 & -0.35 ( -0.91 to 0.22$)$ & 0.229 & $-0.01(-0.34$ to 0.32$)$ & 0.952 \\
\hline Model 1+BMI $z$-score & $-0.35(-0.86$ to 0.17$)$ & 0.183 & $0.29(-0.04$ to 0.61$)$ & 0.084 & $-0.39(-0.95$ to 0.18$)$ & 0.176 & $-0.02(-0.35$ to 0.32$)$ & 0.919 \\
\hline \multicolumn{9}{|l|}{ Normal weight } \\
\hline Model 1 & $-0.53(-1.17$ to 0.11$)$ & 0.103 & $0.12(-0.37$ to 0.60$)$ & 0.641 & $-0.16 \mathrm{c}(-0.96$ to 0.65$)$ & 0.699 & $0.03(-0.49$ to 0.55$)$ & 0.914 \\
\hline \multicolumn{9}{|l|}{ Overweight/obese } \\
\hline Model 1 & $-0.21(-1.04$ to 0.63$)$ & 0.620 & $0.31(-0.16$ to 0.77$)$ & 0.194 & $-0.54(-1.38$ to 0.30$)$ & 0.206 & $-0.16(-0.62$ to 0.31$)$ & 0.496 \\
\hline
\end{tabular}

The values presented $(\beta, \mathrm{CI})$ are for salt intake (g/day), as estimated by linear regression models, with ABPM values as the dependent variables. $\beta$ regression coefficient, $C I$ confidence interval, $S B P$ systolic blood pressure, $D B P$ diastolic blood pressure, $B M I$ body mass index

${ }^{\text {a }}$ Model 1 is adjusted for age (in months), height (in $\mathrm{cm}$ ), family history of hypertension (at least one parent or sibling reported to be affected), and class of birthweight for gestational age (according to the population-based Canadian reference curves [22]) and additionally for BMI $z$-score when duly indicated

${ }^{\mathrm{b}}$ Note that the effect of salt intake on daytime SBP was significant in overweight/obese boys but not significant in the normal weight boys ( $p$ for interaction $=0.043$ )

In the multiple linear regression analysis, daytime SBP increased by $0.56 \mathrm{mmHg}$ [95\% confidence interval (CI) $0.11-1.01 ; p=0.014]$ per gram of salt intake in boys, even after adjustment for BMI $z$-score, whereas no significant effect was found in daytime DBP or in nighttime SBP or DBP. Daytime SBP increased by $1.00 \mathrm{mmHg}(95 \%$
CI $0.40-1.59 ; p=0.001)$ per gram of salt in overweight/ obese boys, while the effect of salt on daytime SBP was not significant among normal weight boys ( $p$ for interaction $=0.008$ ). No effect was found in girls (Table 2). The estimated salt intake was not associated with the dipping profile.

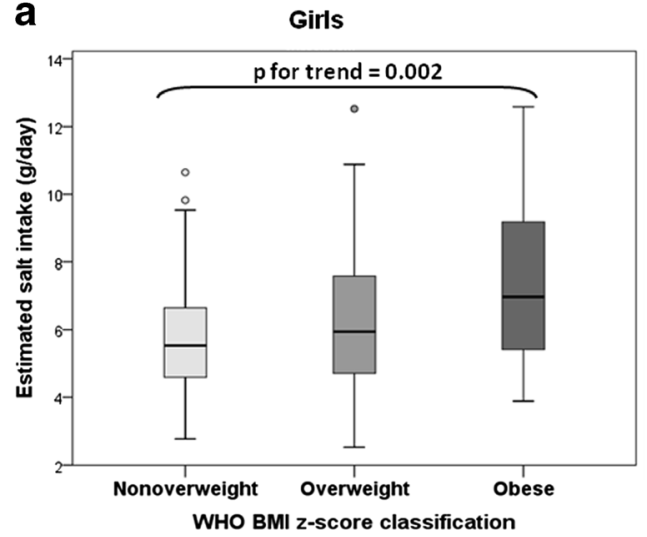

Fig. 1 Estimated salt intake by classes of body mass index (BMI). The criteria (BMI $z$-scores) for classifying the children into the groups of normal weight, overweight and obese are those of the World Health Organization $(W H O)$ [24]. The estimated salt intake is expressed as the b Boys

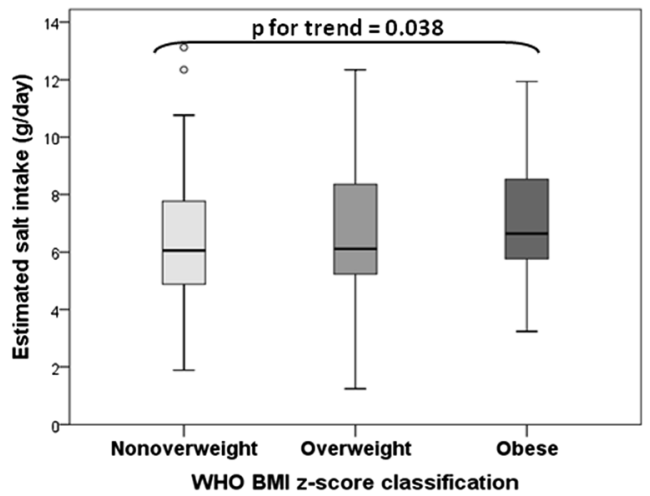

median value (horizontal line in each box) and the 25 th and 75 th percentiles (bottom and top of boxes, respectively). Error bar Standard deviation. $p$ values for linear trend across groups were calculated by linear regression, adjusting for age (in months) 

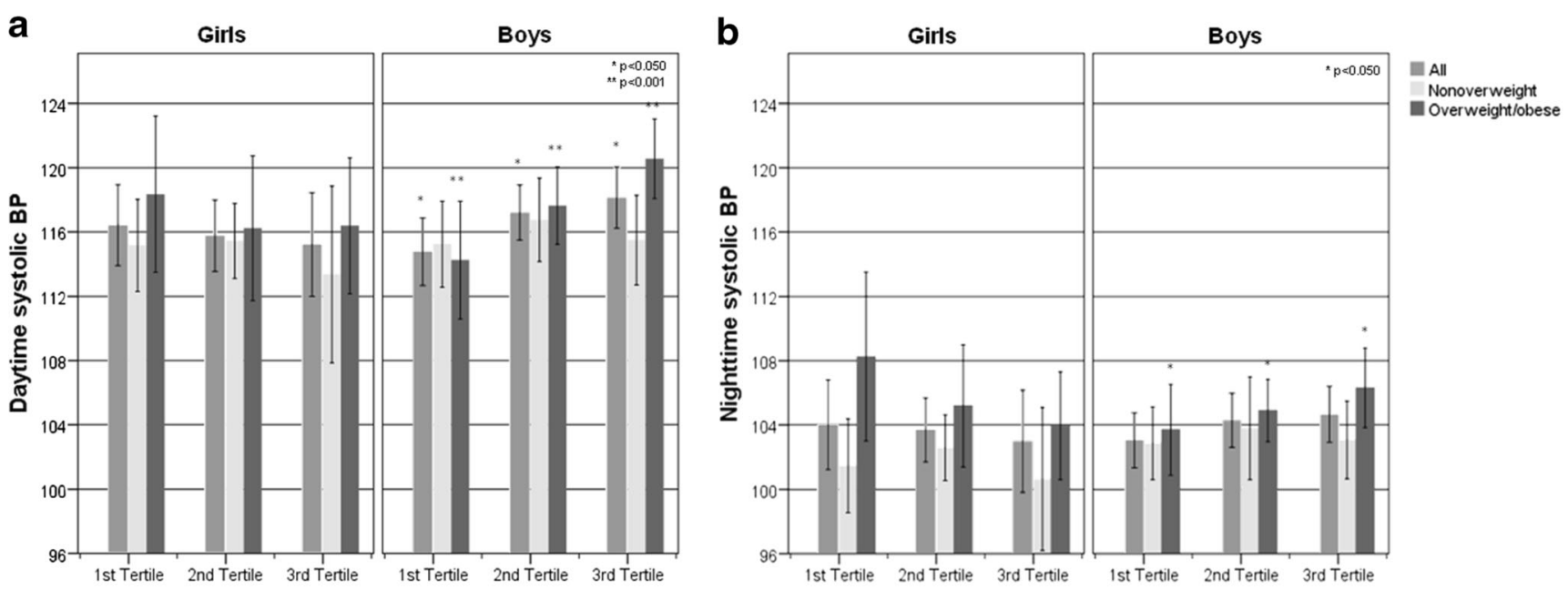

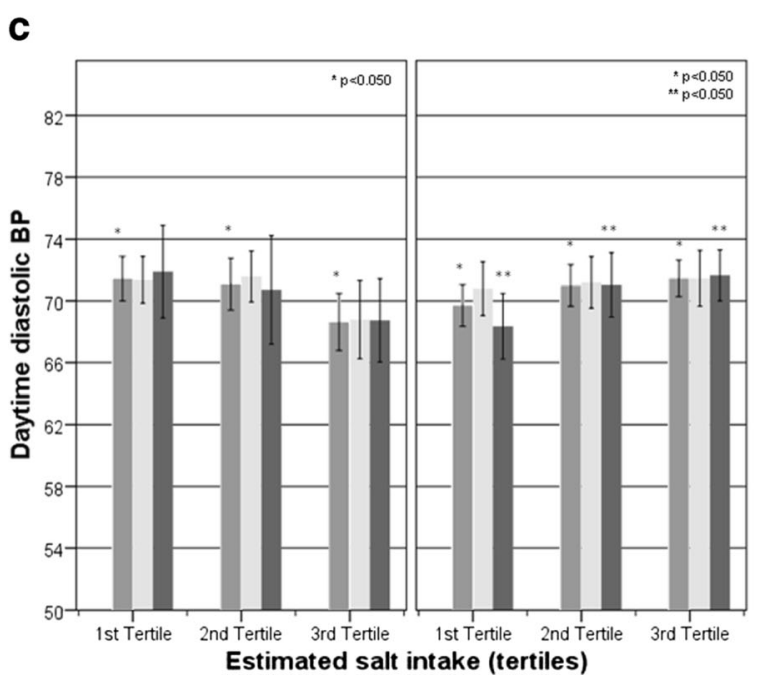

Fig. 2 Mean daytime and nighttime systolic and diastolic blood pressure (BP) by tertiles of estimated salt intake and weight status, in girls and boys separately. a, c Means and $95 \%$ confidence intervals (CI) of daytime systolic (a) and diastolic (c) blood pressure $(B P)$ in girls and boys separately, according to tertiles of estimated salt intake. $\mathbf{b}, \mathbf{d}$ Means and $95 \%$ CI of nighttime systolic (b) and diastolic (d) BP in

\section{Discussion}

In this sample of Southern European healthy prepubertal children, we observed an average estimated salt intake of $6.5 \pm$ $2.2 \mathrm{~g}$ per day, which is not only above two different recommendations adapted for children [28, 29], but also above the World Health Organization recommendations for the general adult population (below $5 \mathrm{~g}$ /day) [30]. This excessive salt intake was even higher among overweight/obese children. Interestingly, a different effect of salt on BP was found between genders: in overweight/obese boys, a higher salt intake was associated with increased BP levels, especially daytime SBP, whereas, in girls, the effect of salt intake on adjusted values of BP was not significant. The association between salt intake and BP is well established $[9,10]$, but

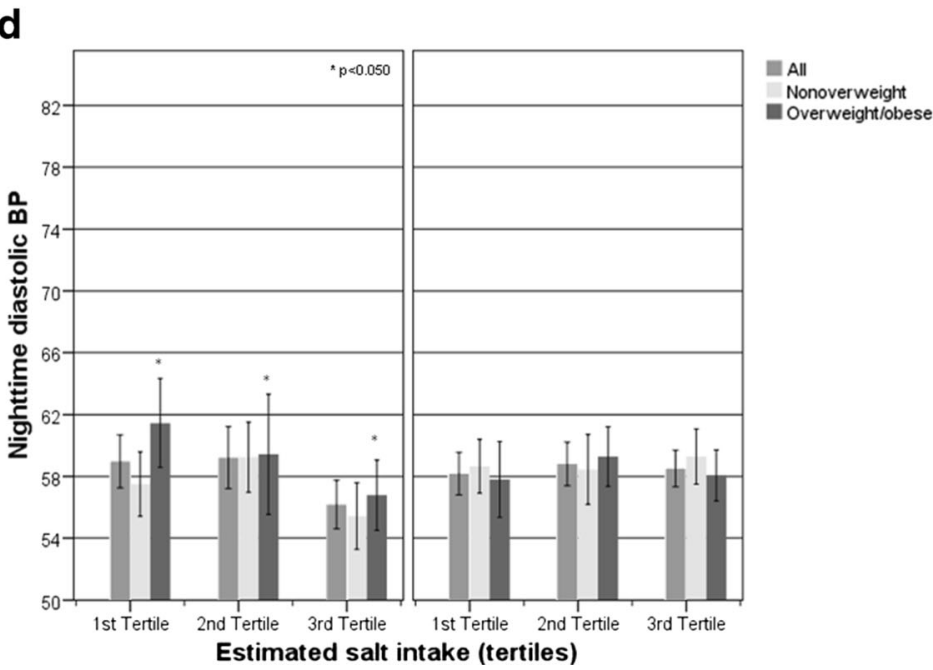

girls and boys separately according to tertiles of estimated salt intake. The tertiles of estimated salt intake (1st, 2nd, 3rd: $\leq 5.29,5.29-7.06$, $>7.06$, respectively) were defined based on data collected on all enrolled participants. $p$ values for linear trend across tertiles of salt intake were calculated by linear regression, adjusting for age (in months)

few studies in children used ABPM before, which makes our results of special interest.

\section{Salt intake}

The exact daily salt requirements in children remain to be defined and current recommendations for adequate salt consumption are only empirical expert opinions [31], leading us to take into consideration two different recommendations. Even so, there is no doubt that one should be worried that almost $75 \%$ of young children in our sample had salt intake above the threshold defined for adults [30]. Previous studies performed in Portugal have already showed that we are among the countries in Europe with the highest intake of salt, estimated as $10.7 \mathrm{~g}$ /day in the last population-based survey in adults 
[19], and $7.8 \mathrm{~g} /$ day in a study in children (aged 10-12 years) [32]. Data from our sample reveals that even under 10 years of age, Portuguese children's salt intake is above current recommendations.

\section{Association between salt and BP}

We describe a trend towards an increase of BP with salt intake only in boys, with a daytime SBP magnitude of $0.56 \mathrm{mmHg}$ per gram of salt per day. This finding is consistent with those reported by earlier epidemiological studies $[16,21]$, and the magnitude of this association is very similar to the findings of a meta-analysis of controlled trials in children $[9,10]$. Some studies in prepubertal children did not find an association between salt and BP, leading the authors of these studies to hypothesize that salt sensitivity would only begin to increase at older ages [21,33]. Our results suggest that the different results arise because girls and boys are usually analyzed together. Also, it should be emphasized that we evaluated BP by $\mathrm{ABPM}$, which is considered to be the most accurate measure to evaluate the BP burden in children [34], while most of the studies cited here measured office BP.

\section{Association between salt, BP, and obesity}

Boys showed an increase in BP with higher salt intake, with the increase stronger in the overweight/obese group than in the normal weight group. These results are consistent with the findings of Yang et al. [16] who reported that overweight/ obese US children presented a greater risk for hypertension associated with salt intake than normal weight children. These authors reported a $1.5 \mathrm{mmHg}$ increase in SBP per gram of salt among the overweight/obese (vs. a $0.2 \mathrm{mmHg}$ increase in normal weight children), which is comparable to our finding of $1.0 \mathrm{mmHg}$ increase in daytime SBP per gram of salt in the overweight/obese boys of our study. Elevated BP in obese individuals is usually associated with a volumedependent increase in stroke volume, sodium retention and higher salt sensitivity, probably due to the combined effects of hyperinsulinemia, hyperaldosteronism, and increased activity of the sympathetic nervous system [13, 15]. Hyperinsulinemia is known to be correlated with elevated $\mathrm{BP}$, especially nighttime $\mathrm{BP}$, and is considered to be a herald of hypertension associated with insulin resistance, as well as associated with excessive central sympathetic nervous system activity, increased peripheral resistance and increased sodium reabsorption in the kidney [35]. Thus, it is possible that the larger effect of salt on BP in the overweight/obese boys is the result of the combination of several deleterious mechanisms and a higher salt sensitivity which is already active at a young age. In our study, which mainly included normotensive children, the association found between salt and BP is particularly important.
Although the effect of salt on BP may vary in hypertensive children, the existence of an association in the normotensive range raises additional concerns for public health.

\section{Differences between genders}

We observed a higher salt intake in boys than in girls, a difference which has been described in previous studies $[18,29]$. This association is believed to reflect the different energy requirements of boys and girls, with those of boys being higher and thereby leading to greater food consumption and higher salt intake.

Nonetheless, the differential effect of salt on the BP of males and females requires further explanation. It is well established that premenopausal women have a lower incidence of hypertension than men [36], and female sex hormones are believed to have protective effects against saltinduced increases in BP, possibly by augmenting the renal excretion of sodium [37]. A study in prepubertal children reported that boys and girls at a biologically comparable prepubertal stage showed a 1.5-year difference in chronological age (boys were older), with comparable levels of circulating estrogens [38].

This finding suggests that in our sample of boys and girls of the same age, the girls could actually be at a more advanced pubertal stage, with higher estrogen levels altering the effect of salt on BP and making them less salt sensitive. Indeed, various studies involving prepubertal children have reported significantly higher levels of estrogens in girls than in similarly aged boys $[39,40]$. However, in the absence of sexual hormones measurements and confirmation of pubertal status, we are unable to draw any definite conclusions from our interpretation of these specific results. Another possible explanation for our findings might be related to differences between the sexes in terms of body composition and fat distribution, which are known to occur even before puberty [41], since salt sensitivity is known to be higher in overweight/obese subjects [13]. We also cannot exclude the possibility that our results might represent a chance finding. Future studies which take both sexual hormones and body composition into account may provide an explanation of our findings.

\section{Strengths and limitations}

We evaluated a large population-based sample of young children, which allowed us to compare gender and nutritional status subgroups, which is seldom seen in other studies, especially in children of such a young age. Moreover, the standardized protocol of the cohort evaluation allowed us to adjust for potential confounders of the association between salt and BP, such as body size, early life factors, and family history of hypertension, which could account for part of the genetic and epigenetic influence of salt on BP. Specifically, the adjustment 
for the adequacy of birthweight to gestational age allowed us to account for the inverse association between birthweight and later risk for high BP levels, an association which is now well established and recently reviewed by $\mathrm{Mu}$ et al. [42]. Also, we estimated salt intake by the measurement of sodium excretion in 24-h urine samples, which is considered to be the gold standard [43]. Finally, we chose to evaluate BP by ABPM since this method is more accurate, although it has rarely been used in children to assess the association between salt intake and BP.

Our study is limited by its cross-sectional design, and the associations found between BP and salt intake have to be interpreted with caution. Although sodium excretion in 24-h urine samples is considered to be the gold standard to estimate salt intake [18], it has limitations that should be acknowledged. There is a significant day-to-day variation in sodium excretion, reflecting the variation in salt intake; to increase the accuracy of the estimation it would be necessary to perform multiple 24-h assessments, which is not always feasible. It is also difficult to ensure a complete 24-h collection, particularly in children [31], which is why we submitted urine samples to strict creatininuria validation criteria. However, it should be noted that in the case that urine samples were undercollected (a urine collection over too short a time period is more likely than over too long a time period), then our results would be underestimating salt intake and not the contrary. In our setting and since our aim was to establish the existence of associations between BP levels and salt intake, rather than to classify subjects by their hypertensive status, we decided to use raw BP values instead of SD scores. Nonetheless, the adjustment for age and height in our regression models allowed us to adequately account for the effect of height upon BP levels, without impacting the interpretation of our results in light of the reference value used. Given the regional specificity of diet in terms of salt consumption, studies in different populations are warranted to support the generalizability of our findings.

\section{Conclusions}

A striking proportion of children have an estimated salt intake above all recommendations, even those for adults. Also, higher salt intake was associated with elevated BP in prepubertal boys, and this effect was stronger among the overweight/obese, who also had a higher salt intake. This association was not observed in girls.

Overall, our data and those from other studies reinforce the notion that childhood is a crucial period for future BP values and highlights this period as a target for preventive approaches to be taken. Based on these results, we urge for dietary salt reduction interventions, along with measures to fight obesity, to be implemented as early in life as possible in order to reduce the long-term impact of salt consumption on the quality of health and life of the world's populations. Longitudinal studies are needed to further evaluate the causal relationship between high BP and obesity and the mechanism by which salt intake modulates this relationship.

Acknowledgments The authors gratefully acknowledge the contribution of all members of the research team and staff of G21.

Compliance with ethical standards The ObiKid study was approved by the Ethics Committee of Centro Hospitalar São João, E.P.E. and Faculty of Medicine of the University of Porto and complies with the Helsinki Declaration and current national legislation. Written informed consent from parents [or their legal guardian(s)] and verbal assent from the children were obtained regarding the collection of information and biological samples.

Conflicts of interest None of the authors have any financial or nonfinancial competing interests concerning the study reported here.

Sources of funding This project was supported by FEDER funds from Programa Operacional Factores de Competitividade-COMPETE (FCOMP-01-0124-FEDER-028751) and by national funds from the Portuguese Foundation for Science and Technology, Lisbon, Portugal (PTDC/DTP-PIC/0239/2012). Liane Correia-Costa was supported by the Portuguese Foundation for Science and Technology (grant SFRH/SINTD/95898/2013), and Franz Schaefer was supported by the ERA-EDTA Research Programme and the KfH Foundation for Preventive Medicine.

\section{References}

1. Lim SS, Vos T, Flaxman AD, Danaei G, Shibuya K, Adair-Rohani H, Amann M, Anderson HR, Andrews KG, Aryee M, Atkinson C, Bacchus LJ, Bahalim AN, Balakrishnan K, Balmes J, Barker-Collo S, Baxter A, Bell ML, Blore JD, Blyth F, Bonner C, Borges G, Bourne R, Boussinesq M, Brauer M, Brooks P, Bruce NG, Brunekreef B, Bryan-Hancock C, Bucello C, Buchbinder R, Bull F, Burnett RT, Byers TE, Calabria B, Carapetis J, Carnahan E, Chafe Z, Charlson F, Chen H, Chen JS, Cheng AT-A, Child JC, Cohen A, Colson KE, Cowie BC, Darby S, Darling S, Davis A, Degenhardt L, Dentener F, Des Jarlais DC, Devries K, Dherani M, Ding EL, Dorsey ER, Driscoll T, Edmond K, Ali SE, Engell RE, Erwin PJ, Fahimi S, Falder G, Farzadfar F, Ferrari A, Finucane MM, Flaxman S, Fowkes FGR, Freedman G, Freeman MK, Gakidou E, Ghosh S, Giovannucci E, Gmel G, Graham K, Grainger R, Grant B, Gunnell D, Gutierrez HR, Hall W, Hoek HW, Hogan A, Hosgood HD, Hoy D, Hu H, Hubbell BJ, Hutchings SJ, Ibeanusi SE, Jacklyn GL, Jasrasaria R, Jonas JB, Kan H, Kanis JA, Kassebaum N, Kawakami N, Khang Y-H, Khatibzadeh S, Khoo J-P, Kok C, Laden F, Lalloo R, Lan Q, Lathlean T, Leasher JL, Leigh J, Li Y, Lin JK, Lipshultz SE, London S, Lozano R, Lu Y, Mak J, Malekzadeh R, Mallinger L, Marcenes W, March L, Marks R, Martin R, McGale P, McGrath J, Mehta S, Mensah GA, Merriman TR, Micha R, Michaud C, Mishra V, Mohd Hanafiah K, Mokdad AA, Morawska L, Mozaffarian D, Murphy T, Naghavi M, Neal B, Nelson PK, Nolla JM, Norman R, Olives C, Omer SB, Orchard J, Osborne R, Ostro B, Page A, Pandey KD, Parry CDH, Passmore E, Patra J, Pearce N, Pelizzari PM, Petzold M, Phillips MR, Pope D, Pope CA, Powles J, Rao M, Razavi H, Rehfuess EA, Rehm JT, Ritz B, Rivara FP, Roberts T, Robinson C, Rodriguez-Portales JA, Romieu I, Room R, Rosenfeld LC, Roy A, Rushton L, Salomon JA, Sampson U, Sanchez-Riera L, 
Sanman E, Sapkota A, Seedat S, Shi P, Shield K, Shivakoti R, Singh GM, Sleet DA, Smith E, Smith KR, Stapelberg NJC, Steenland K, Stöckl H, Stovner LJ, Straif K, Straney L, Thurston GD, Tran JH, Van Dingenen R, van Donkelaar A, Veerman JL, Vijayakumar L, Weintraub R, Weissman MM, White RA, Whiteford H, Wiersma ST, Wilkinson JD, Williams HC, Williams W, Wilson N, Woolf AD, Yip P, Zielinski JM, Lopez AD, Murray CJL, Ezzati M, AlMazroa MA, Memish ZA (2012) A comparative risk assessment of burden of disease and injury attributable to 67 risk factors and risk factor clusters in 21 regions, 1990-2010: a systematic analysis for the Global Burden of Disease Study 2010. Lancet 380:2224-2260

2. Rosner B, Cook NR, Daniels S, Falkner B (2013) Childhood blood pressure trends and risk factors for high blood pressure: the NHANES experience 1988-2008. Hypertension 62:247-254

3. Chen X, Wang Y (2008) Tracking of blood pressure from childhood to adulthood: a systematic review and meta-regression analysis. Circulation 117:3171-3180

4. Berenson GS (2002) Childhood risk factors predict adult risk associated with subclinical cardiovascular disease. The Bogalusa Heart Study. Am J Cardiol 90:3L-7L

5. Juonala M, Magnussen CG, Berenson GS, Venn A, Burns TL, Sabin MA, Srinivasan SR, Daniels SR, Davis PH, Chen W, Sun C, Cheung M, Viikari JS, Dwyer T, Raitakari OT (2011) Childhood adiposity, adult adiposity, and cardiovascular risk factors. N Engl J Med 365:1876-1885

6. Lauer RM, Mahoney LT, Clarke WR (1986) Tracking of blood pressure during childhood: the Muscatine Study. Clin Exp Hypertens A 8:515-537

7. Stabouli S, Papakatsika S, Kotsis V (2011) The role of obesity, salt and exercise on blood pressure in children and adolescents. Expert Rev Cardiovasc Ther 9:753-761

8. Flynn J (2013) The changing face of pediatric hypertension in the era of the childhood obesity epidemic. Pediatr Nephrol 28: 1059-1066

9. He FJ, MacGregor GA (2006) Importance of salt in determining blood pressure in children: meta-analysis of controlled trials. Hypertension 48:861-869

10. Aburto NJ, Ziolkovska A, Hooper L, Elliott P, Cappuccio FP, Meerpohl JJ (2013) Effect of lower sodium intake on health: systematic review and meta-analyses. BMJ 346:f1326

11. Geleijnse JM, Hofman A, Witteman JC, Hazebroek AA, Valkenburg HA, Grobbee DE (1997) Long-term effects of neonatal sodium restriction on blood pressure. Hypertension 29:913-917

12. Brion M-J, Ness AR, Davey Smith G, Emmett P, Rogers I, Whincup P, Lawlor DA (2008) Sodium intake in infancy and blood pressure at 7 years: findings from the Avon Longitudinal Study of Parents and Children. Eur J Clin Nutr 62:1162-1169

13. Fujita $\mathrm{T}$ (2010) Mineralocorticoid receptors, salt-sensitive hypertension, and metabolic syndrome. Hypertension 55:813-818

14. Chen J, Gu D, Huang J, Rao DC, Jaquish CE, Hixson JE, Chen C-S, Chen J, Lu F, Hu D, Rice T, Kelly TN, Hamm LL, Whelton PK, He J (2009) Metabolic syndrome and salt sensitivity of blood pressure in non-diabetic people in China: a dietary intervention study. Lancet 373:829-835

15. Rocchini AP, Key J, Bondie D, Chico R, Moorehead C, Katch V, Martin M (1989) The effect of weight loss on the sensitivity of blood pressure to sodium in obese adolescents. N Engl J Med 321:580-585

16. Yang Q, Zhang Z, Kuklina EV, Fang J, Ayala C, Hong Y, Loustalot F, Dai S, Gunn JP, Tian N, Cogswell ME, Merritt R (2012) Sodium intake and blood pressure among US children and adolescents. Pediatrics 130:611-619

17. Woodruff SJ, Fryer K, Campbell T, Cole M (2014) Associations among blood pressure, salt consumption and body weight status of students from south-western Ontario. Public Health Nutr 17:1114 1119

18. Brown IJ, Tzoulaki I, Candeias V, Elliott P (2009) Salt intakes around the world: implications for public health. Int $\mathrm{J}$ Epidemiol 38:791-813

19. Polonia J, Martins L, Pinto F, Nazare J (2014) Prevalence, awareness, treatment and control of hypertension and salt intake in Portugal: changes over a decade. The PHYSA study. J Hypertens 32:1211-1221

20. Larsen PS, Kamper-Jorgensen M, Adamson A, Barros H, Bonde JP, Brescianini S, Brophy S, Casas M, Charles M-AA, Devereux G, Eggesbo M, Fantini MP, Frey U, Gehring U, Grazuleviciene R, Henriksen TB, Hertz-Picciotto I, Heude B, Hryhorczuk DO, Inskip H, Jaddoe VWV, Lawlor DA, Ludvigsson J, Kelleher C, Kiess W, Koletzko B, Kuehni CE, Kull I, Kyhl HB, Magnus P, Momas I, Murray D, Pekkanen J, Polanska K, Porta D, Poulsen G, Richiardi L, Roeleveld N, Skovgaard AM, Sram RJ, StrandbergLarsen K, Thijs C, Van Eijsden M, Wright J, Vrijheid M, Andersen A-MNM, Kamper-Jørgensen M, Adamson A, Barros H, Bonde JP, Brescianini S, Brophy S, Casas M, Charles M-AA, Devereux G, Eggesbø M, Fantini MP, Frey U, Gehring U, Grazuleviciene R, Henriksen TB, Hertz-Picciotto I, Heude B, Hryhorczuk DO, Inskip H, Jaddoe VWV, Lawlor DA, Ludvigsson J, Kelleher C, Kiess W, Koletzko B, Kuehni CE, Kull I, Kyhl HB, Magnus P, Momas I, Murray D, Pekkanen J, Polanska K, Porta D, Poulsen G, Richiardi L, Roeleveld N, Skovgaard AM, Sram RJ, StrandbergLarsen K, Thijs C, Van Eijsden M, Wright J, Vrijheid M, Andersen A-MNM (2013) Pregnancy and birth cohort resources in europe: a large opportunity for aetiological child health research. Paediatr Perinat Epidemiol 27:393-414

21. He FJ, Marrero NM, Macgregor GA (2008) Salt and blood pressure in children and adolescents. J Hum Hypertens 22:4-11

22. Kramer MS, Platt RW, Wen SW, Joseph KS, Allen A, Abrahamowicz M, Blondel B, Breart G, Bréart G, Breart G (2001) A new and improved population-based Canadian reference for birth weight for gestational age. Pediatrics 108:E35

23. Durão C, Severo M, Oliveira A, Moreira P, Guerra A, Barros H, Lopes C, Durao C, Severo M, Oliveira A, Moreira P, Guerra A, Barros H, Lopes C (2014) Evaluating the effect of energy-dense foods consumption on preschool children's body mass index: a prospective analysis from 2 to 4 years of age. Eur J Nutr 54:835-843

24. De Onis M, Onyango AW, Borghi E, Siyam A, Nishida C, Siekmann J (2007) Development of a WHO growth reference for school-aged children and adolescents. Bull World Heal Organ 85: 660-667

25. Flynn JT, Daniels SR, Hayman LL, Maahs DM, McCrindle BW, Mitsnefes M, Zachariah JP, Urbina EM (2014) Update: ambulatory blood pressure monitoring in children and adolescents: a scientific statement from the American Heart Association. Hypertension 63: $1116-1135$

26. National High Blood Pressure Education Program Working Group on High Blood Pressure in Children and Adolescents (2004) The fourth report on the diagnosis, evaluation, and treatment of high blood pressure in children and adolescents. Pediatrics 114:555-576

27. Remer T, Neubert A, Maser-Gluth C (2002) Anthropometry-based reference values for 24-h urinary creatinine excretion during growth and their use in endocrine and nutritional research. Am J Clin Nutr 75:561-569

28. Instituite of Medicine (IOM) (2000) DRI dietary reference intakes: applications in dietary assessment. National Academy Press, Washington DC. Available at:: http://www.ncbi.nlm.nih.gov/ books/NBK222890/pdf/Bookshelf NBK222890.pdf. Accessed 23 July 2015 
29. Marrero NM, He FJ, Whincup P, Macgregor GA (2014) Salt intake of children and adolescents in South London: consumption levels and dietary sources. Hypertension 63:1026-1032

30. World Health Organization (WHO) (2012) Sodium intake for adults and children. World Health Organization, Geneva. Available at: http://www.who.int/nutrition/publications/guidelines/sodium intake_printversion.pdf. Accessed 1 June 2015

31. Juncos LI (2014) Salt intake in childhood and adolescence. Hypertension 63:911-912

32. Cotter J, Cotter MJ, Oliveira P, Cunha P, Polonia J, Polónia J (2013) Salt intake in children 10-12 years old and its modification by active working practices in a school garden. J Hypertens 31: 1966-1971

33. Shi L, Krupp D, Remer T (2014) Salt, fruit and vegetable consumption and blood pressure development: a longitudinal investigation in healthy children. Br J Nutr 111:662-671

34. Flynn JT, Urbina EM (2012) Pediatric ambulatory blood pressure monitoring: indications and interpretations. J Clin Hypertens 14: 372-382

35. Kotsis V, Stabouli S, Papakatsika S, Rizos Z, Parati G (2010) Mechanisms of obesity-induced hypertension. Hypertens Res 33: 386-393

36. Roger VL, Go AS, Lloyd-Jones DM, Benjamin EJ, Berry JD, Borden WB, Bravata DM, Dai S, Ford ES, Fox CS, Fullerton HJ, Gillespie C, Hailpern SM, Heit JA, Howard VJ, Kissela BM, Kittner SJ, Lackland DT, Lichtman JH, Lisabeth LD, Makuc DM, Marcus GM, Marelli A, Matchar DB, Moy CS, Mozaffarian D, Mussolino ME, Nichol G, Paynter NP, Soliman EZ, Sorlie PD, Sotoodehnia N, Turan TN, Virani SS, Wong ND, Woo D, Turner MB (2012) Executive summary: heart disease and stroke statistics-2012 update: a report from the American Heart Association. Circulation 125:188-197

37. Pechère-Bertschi A, Burnier M (2004) Female sex hormones, salt, and blood pressure regulation. Am J Hypertens 17:994-1001

38. Shi L, Remer T, Buyken AE, Hartmann MF, Hoffmann P, Wudy SA (2010) Prepubertal urinary estrogen excretion and its relationship with pubertal timing. Am J Physiol Endocrinol Metab 299: E990-997

39. Klein KO, Baron J, Colli MJ, McDonnell DP, Cutler GB (1994) Estrogen levels in childhood determined by an ultrasensitive recombinant cell bioassay. J Clin Invest 94:2475-2480

40. Courant F, Aksglaede L, Antignac J-PP, Monteau F, Sorensen K, Andersson A-MM, Skakkebaek NE, Juul A, Le Bizec B (2010) Assessment of circulating sex steroid levels in prepubertal and pubertal boys and girls by a novel ultrasensitive gas chromatographytandem mass spectrometry method. J Clin Endocrinol Metab 95: 82-92

41. He Q, Horlick M, Thornton J, Wang J, Pierson RN, Heshka S, Gallagher D (2002) Sex and race differences in fat distribution among Asian, African-American, and Caucasian prepubertal children. J Clin Endocrinol Metab 87:2164-2170

42. Mu M, Wang S-F, Sheng J, Zhao Y, Li H-Z, Hu C-L, Tao F-B (2012) Birth weight and subsequent blood pressure: a meta-analysis. Arch Cardiovasc Dis 105:99-113

43. World Health Organization (2011) Strategies to monitor and evaluate population sodium consumption and sources of sodium in the diet: report of a joint technical meeting convened by WHO and the Government of Canada. World Health Organization, Geneva. Available at: http://apps.who.int/iris/bitstream/10665/44614/1/ 9789241501699_eng.pdf?ua=1. Accessed 23 July 2015 